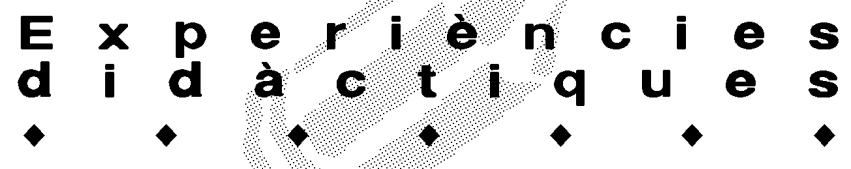

\section{ACTIVITATS MATEMÀTIQUES AL VOLTANT DEL MÓN CASTELLER}

\author{
Montserrat Güell Giménez. Mestra del CEIP Rubió i Ors. Reus
}

\section{Introducció}

La matemàtica és una forma, un llenguatge més, que tenim per representar la realitat. Però molts cops les activitats de classe no deixen d'ésser un seguit d'exercicis inconnexos entre ells i allunyats del món que ens envolta, perquè, tot i que existeix una vida fora de l'escola, aquesta en molts casos no penetra dins de l'aula.

A la classe hem de procurar desenvolupar activitats que permetin construir el coneixement amb l'assignació de significats, i perquè això sigui possible, tal com afirma Gimènez (1997), és necessari que en l'activitat proposada "es compleixi més d'un objectiu i fomenti la motivació, s'integrin continguts diversos, es permeti la reflexió posterior sobre el propi treball i es promoguin activitats d'alt rang". La resolució de problemes oberts extrets del context quotidià és una eina a emprar si pretenem que els alumnes que tenim a classe vagin construint el seu propi coneixement. Girondo (2000) ens diu: "La resolució de problemes es considera el lloc on es produeixen coneixements, és a dir, on s'apliquen les eines de què es disposa a una situació nova; aquesta transferència de coneixement, en adaptar-se a una nova situació, ampliarà en alguna mesura el significat, i per tant, es pot considerar que es produeix coneixement nou".

L'activitat que es presenta és una situació oberta contextualitzada que permet aquesta connexió entre un fet quotidià, una jornada castellera, i l'escola.

Ens proposem que els alumnes de primer de cicle superior d'educació primària realitzin un seguit de tallers matemàtics al voltant del món casteller. Aquests tallers són: Taller 1 "Els castells" (Matemàtica castellera. Fem castells). Taller 2 "Vestim la colla" (Fem faixes i mocadors. La millor oferta). Taller 3 "Geometria a la plaça del Mercadal" (Cerca de geometria a la plaça i definició dels elements trobats. Models de cossos geomètrics de la plaça). Taller 4 "Diada Castellera/organització" (Citem les colles. I nosaltres... on som?).

Aquesta activitat sobre els castells és un treball interdisciplinari en què es poden organitzar activitats sobre les àrees següents:

\section{Àrees}

Llengua

\section{Possibles activitats}

- Treball específic del vocabulari del món casteller.

- Elaboració de cartells publicitaris de

la jornada.

- Cròniques i noticies de les principals construccions realitzades.

- Entrevistes a les colles locals.

- Reportatges des de la plaça...

- Elaboració de murals de síntesi de l'activitat.

C. Medi Social - El fet casteller al Camp de Tarragona.

- Estudi de les principals colles i construccions.

- Castells i Festa Major.

C. Medi Natural $\cdot$ Castells i seguretat. Mesures preventives.

Plàstica - Confecció de cartells publicitaris de la diada castellera.

- Disseny i fabricació de guardons i records.

Música - La música dels castells. Principals melodies.

- Els instruments que acompanyen els castells.

Educació Física - Activitats físiques que faciliten les construccions de castells.

- Aixecar petites construccions de dos o tres pisos.

\section{Objectius generals}

- Valorar les matemàtiques com a eina útil per comprendre el món que ens envolta i per actuar sobre el seu entorn immediat.

- Utilitzar els llenguatges verbal, visual i simbòlic per descriure, representar i comunicar situacions i experiències reals 0 simulades, i també per interpretar-les.

- Comprendre les operacions aritmètiques (concepte i algorisme) i conèixer com i quan s'ha d'utilitzar una funció específica.

- Analitzar i interpretar models geomètrics com a 


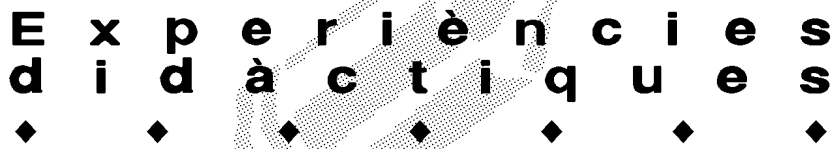

representacions de regions concretes de l'espai real.

- Triar, descriure i classificar cossos a partir de models establerts.

- Utilitzar les matemàtiques que coneix l'alumne per provar de resoldre problemes i situacions diverses triant, d'entre els recursos que té, el que consideri més adient i explicant-ne l'elecció.

\section{Continguts}

Procediment

- Mesura directa, amb unitats convencionals (quilograms, grams, metres, centímetres).

- Comparació i ordenació de mesures.

- Utilització d'instruments per mesurar (estàndard: bàscula de bany, metre... i instruments ad hoc: visuals prenent com a referència un objecte mesurable).

- Arrodoniment de mesures directes.

- Utilització de taules com a organitzadors de la informació.
- Lectura de l'enunciat del problema, aclarint el significat dels termes, i explicació oral, en llenguatge col-loquial, de la situació descrita en el problema.

- En un problema cercar les relacions entre els valors coneguts i els desconeguts.

- Construcció de models que simulin la realitat, guardant una proporció entre model i realitat.

- Utilització de coordenades polars i cartesianes.

Fets i conceptes

- Mesures de longitud i de massa.

- Escales.

- Sistemes de referència al pla: posició.

- Coordenades cartesianes.

- Coordenades polars.

- Figures geomètriques a l'espai: cossos superfícies, línies.

- Elements geomètrics: vèrtex, aresta, cares, angles...

- Relacions geomètriques: paral-lelisme, perpendicularitat...

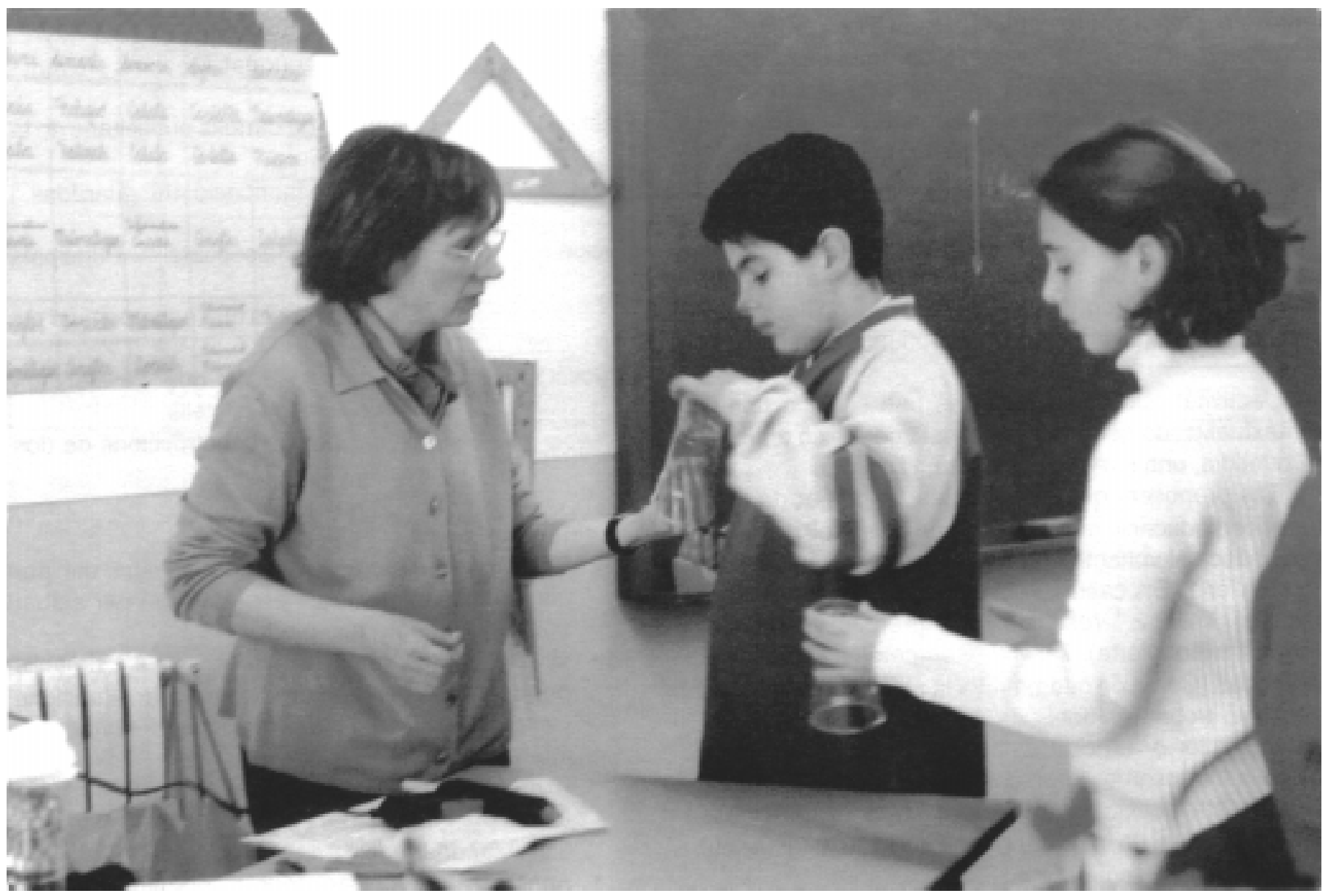




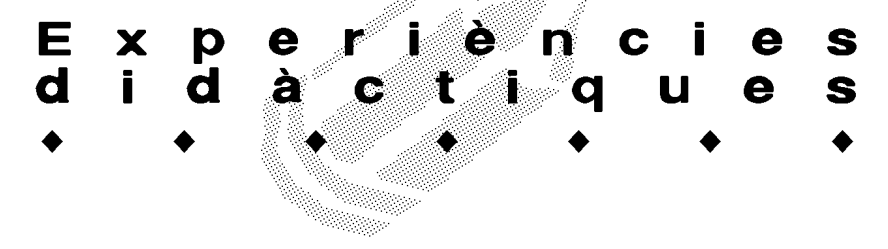

Actituds, valors i normes

- Apreciació en la vida quotidiana dels aspectes que poden ser definits i expressats a través de la matemàtica.

- Interès per l'intercanvi d'informacions, argumentacions $\mathrm{i}$ experiències amb els companys $\mathrm{i}$ el professorat.

- Valoració positiva del propi esforç per arribar a resoldre una situació matemàtica.

- Consideració de l'error com a estímul i element informatiu per a iniciatives noves.

- Elaboració i presentació acurada de tota mena de treballs.

- Recreació mitjançant l'ús d'elements lúdics que comportin un treball matemàtic.

\section{Metodologia de treball}

Agrupaments, suport i espai. Els grups de sisè que faran els tallers són de 24 alumnes, dos d'ells amb necessitats educatives especials a cada aula. Durant el treball de tallers entra dins el grup la mestra de reforç del cicle.

Els alumnes s'organitzaran en quatre grups, un per taller, de cinc/sis membres cada grup.

Les taules de la classe estan agrupades de sis en sis, perquè el mestre o un altre professor que intervingui en el grup tingui també el seu espai; d'aquesta forma els alumnes disposen de més amplitud per poder realitzar les seves activitats.

Els tallers, amb les propostes de treball i els materials necessaris per a desenvolupar-les, estaran situats al racó de matemàtica de la classe. El guió conductor de cada taller estarà ja classificat en arxivadors tipus minuta, $i$ tot el material necessari per a cada taller estarà col-locat en cistelles.

\section{Material}

Cada taller disposarà de material propi.

- Taller 1 "E/s castells": Cinta mètrica, regle, balances, bàscula de bany, folis, gots o pots de paper, tisores, cartolina o cartró, fesols o cigrons, pistola termoselladora (l'ha d'utilitzar sols el mestre), pega i cinta adhesiva.

- Taller 2 "Vestir la colla": Un retall de roba, tisores, paper continu, regle, cinta mètrica, guix de roba, propostes de preus de pantalons i camises.

- Taller 3 "Geometria a la plaça del Mercadal de Reus": Fotografies d'elements de la plaça (Ajuntament, casa Navàs, porxos, empedrat de la plaça, altres cases singulars, llums...). Fitxes amb requadre marcat amb dibuix de l'element estudiat.
Fitxes de reconeixement amb els principals cossos geomètrics, figures planes, línies... Cartolina, pega, tisores, regle. Models de com dibuixar i fer cossos geomètrics.

- Taller 4 "Diada castellera-organització": Plànols de la plaça. Fulls d'acetat amb les coordenades polars. Fulls de la plaça amb les coordenades cartesianes o rectangulars. Plànols de la ciutat amb les seves coordenades (còpies). Itinerari de desplaçament. Llista de preus de segells segons destinació i modalitat. Models de segells existents de curs legal.

\section{Temporització}

Les sessions de treball en tallers són dues hores setmanals. En total s'invertiran 10 sessions: A la motivació, presentació dels tallers i organització es dedicarà una sessió. Per a cada taller es dedicaran dues sessions (8 sessions en total). Per a la síntesi i avaluació es dedicarà 1 sessió.

\section{Sessió primera: Motivació, presentació i organització}

Cada dos any a Reus s'organitza una jornada castellera on, a més de les dues colles locals, Xiquets i Ganxets, es convida altres colles destacades del món casteller. Aprofitant aquest fet i que alguns nens de les classes són membres de les colles, es pot organitzar l'activitat. És interessant anar recopilant les cròniques dels diaris dels anys anteriors per saber les principals construccions fetes $i$ introduir una mica de vocabulari bàsic del món casteller: nom dels castells, pom de dalt, anxaneta, aixecador, els dosos, fer llenya, folre, manilles, fer l'aleta...

A partir d'aquí ens podem anar preguntant: Quants homes es necessiten per fer un castell dels grossos? Quant de pes ha de suportar un casteller que està en el pis de baix? A quina alçada arriba un castell de nou? Quina altura té comparat amb d'altres edificis de la ciutat?... i moltes preguntes més que sorgiran a la classe.

Per donar-hi resposta i saber-ne més s'ha organitzat uns tallers. En aquest moment la mestra presentarà cada taller i perfilarà què s'ha de fer i què es pretén mitjançant les activitats proposades. També es remarcarà que en cada taller hi ha el guió on s'observa tot el treball a fer desenvolupat. S'incidirà en alguns punts que d'antuvi la mestra preveu que poden portar més entrebancs; per exemple, les coordenades polars per localitzar un punt, escales...

Arribat aquest moment, és important de comentar amb els alumnes que, per agilitar els càlculs i la repre- 


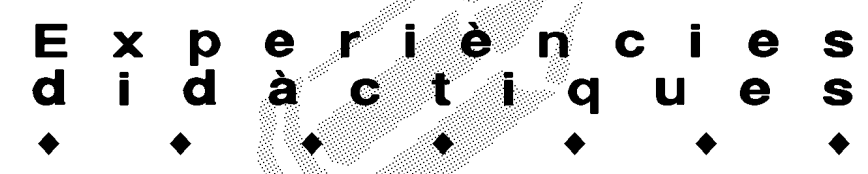

sentació posterior en maquetes, no es tindrà en compte l'espai comprès entre les espatlles dels castellers i el seu cap, i que es cometrà la imprecisió d'aixecar els castells agafant com a referència l'alçada total de la persona tipus de cada pis, com si cada casteller pugés sobre el cap de l'altre.

S'organitzen els grups tenint cura que resultin equilibrats i que en cada un hi hagi alguns dels alumnes que manifestin més dificultats en els seus aprenentatges. Dels alumnes amb necessitats educatives especials també es tindrà cura per a la seva integració al grup.

S'especificarà la normativa per a ús del material, com ha de quedar l'aula després de l'activitat, la necessitat de repartiment de càrrecs dins el grup i el full de valoració de cada sessió de treball que han de complimentar.

Es recalcarà que al final de tots els tallers hi haurà una jornada de síntesi on cada grup disposarà d'un quart d'hora per presentar el seu treball i una hora de debat col-lectiu sobre el gruix de l'activitat, valoració global i redacció d'un autoinforme avaluatiu dels tallers.

\section{Desenvolupament del taller 1: "Els castells" \\ Matemàtica Castellera}

Noтícı: Retall de premsa. Els castellers de Vilafranca, per primer cop a la història, van carregar un 3 de 10 .

CercA: El pes i l'alçada (no cal que siguin membres de cap colla) d'un component tipus de cada estructura del castell. Arrodoneix els resultats per agilitar els càlculs. Presenta les dades en una taula.

DADES BÀsıQUes: Es dóna l'estructura del tres de deu i cada grup ha de decidir les dades que corresponen a cada element (Fig. 1).

A Pensar I Resoldre

Cada grup ha de fer un mínim de tres preguntes sobre aquesta construcció. Algunes de les preguntes que s'han plantejat els nens/es que fan l'activitat són:

\begin{tabular}{|l|c|c|c|}
\hline \multicolumn{1}{|c|}{ Nom del pis } & Alçada del pis/m & $\begin{array}{l}\text { Nombre de } \\
\text { persones }\end{array}$ & $\begin{array}{c}\text { Pes de cada } \\
\text { persona/kg }\end{array}$ \\
\hline Anxaneta & 1,20 & 1 & 20 \\
\hline Acotxador & $\ldots$ & $\ldots$ & $\ldots$ \\
\hline Dosos & & & \\
\hline Setè pis & & & \\
\hline Sisè pis & & & \\
\hline Cinquè pis & & & \\
\hline Quart pis & & & \\
\hline Tercer pis (manilles) & & & \\
\hline Segon pis (folre) & & & \\
\hline Primer pis (pinya) & & & \\
\hline
\end{tabular}

Fig. 1. Estructura i dades del tres de deu

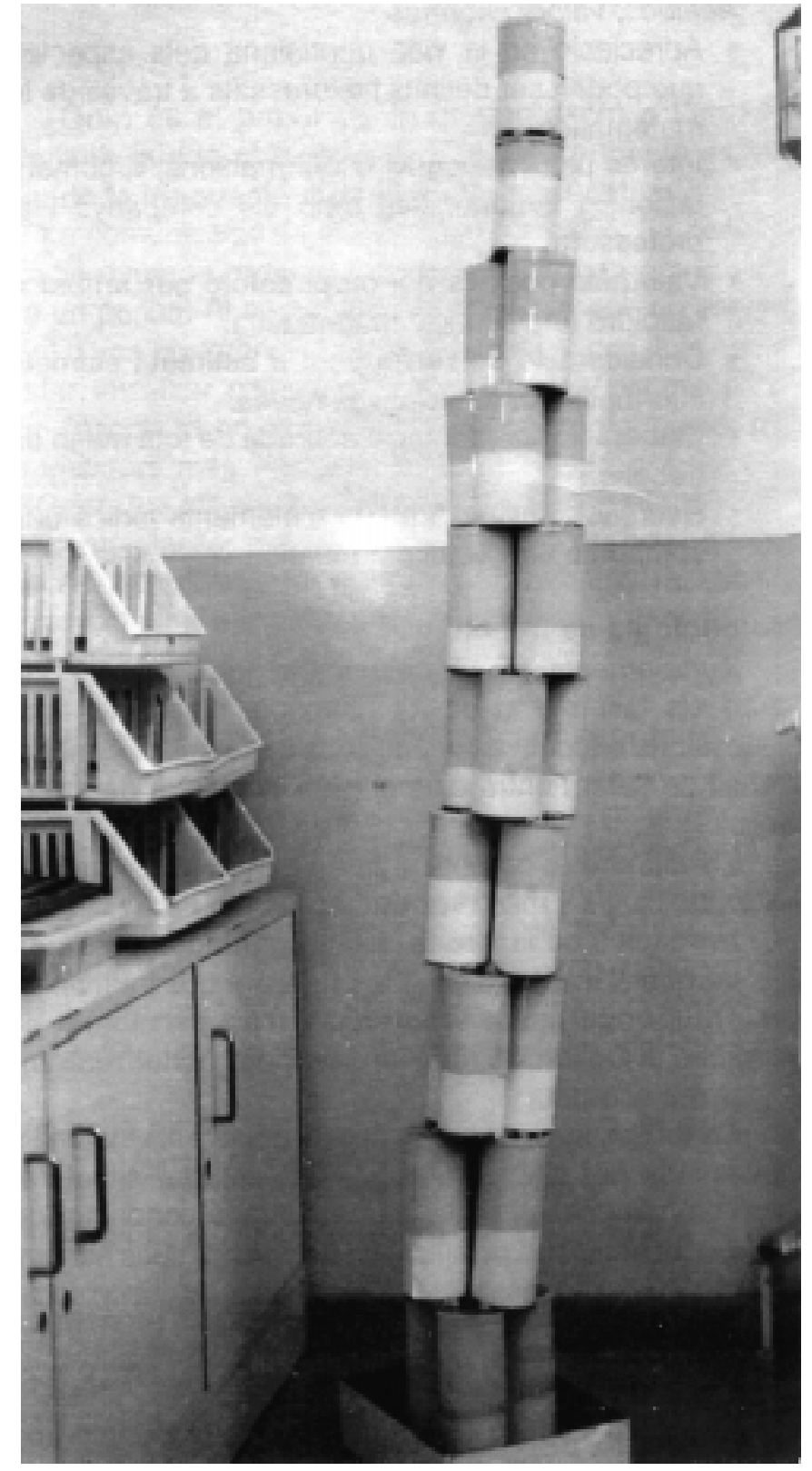

- Quina alçada feia el castell?

- Si en un edifici de la plaça cada planta fa 2,5 m. Què és més alt, el 3 de deu o l'edifici?

- Quantes persones eren necessàries per a fer aquesta construcció castellera?

- Quant pesava tot el castell amb la pinya inclosa?

- Quants quilos suportava la pinya?

- Quants quilos tenien al damunt les manilles?

- Quants quilos aguanten els dosos?

- Abans d'anar a la plaça tota al colla es talla les ungles? Quantes ungles es tallen? 


\section{Comparem Castells}

Notícia: Els "Xiquets de Reus" el dia de la Diada Nacional de Catalunya van carregar un pilar de sis. (Es dóna taula similar al tres de deu amb l'estructura del tres de sis).

A Pensar I Resoldre

Cada grup també és formula preguntes sobre aquesta nova construcció castellera. Algunes d'elles són:

- Quant pesava el pilar que van aixecar els Xiquets l'Onze de setembre?

- Quina alçada feia?

- Quin pes suportava el Xiquet del tercer pis?

- Si el pilar era de sis pisos, quants grallers hi havia?

- A quina alçada d'una casa arribaria el pilar de sis, si cada pis fa $2,5 \mathrm{~m}$ ?

És interessant quan els nois es plantegen preguntes comparatives entre les dues formacions treballades. Mostra de les preguntes d'aquest bloc són:

- Quina diferència de nombre de persones hi ha entre el pilar de sis dels Xiquets i el tres de deu dels de Vilafranca, sense tenir en compte la pinya, el folre i les manilles?

- Quina diferència d'alçada hi ha entre els dos castells? I de persones? Representació gràfica dels resultats.

- Quants quilograms aguantaven els cinquens de cada colla?

- Quin pes aguantava l'anxaneta de cada colla?

- Quina diferència de pes hi ha entre les dues construccions?

Fem Castells

Ja saps com eren les dues construccions treballades (tres de deu i pilar de sis). Ara faràs una construcció a escala del pilar de sis i la d'una altra construcció que vulguis.

Cada got o pot de paper simbolitza un casteller.

Alçada: Per representar l'alçada d'un casteller utilitzarem l'escala 1/10. Així doncs, l'anxaneta, que mesura en realitat $1,20 \mathrm{~m}$, o sigui $120 \mathrm{~cm}$, estarà representada per un got o pot tallat a l'alçada de $12 \mathrm{~cm}$.

Pes: En aquest cas utilitzarem l'escala 1/1000. Així doncs l'anxeneta, que "pesa" $20 \mathrm{~kg}$, o sigui 20000 grams, estarà representada per un pes de 20 grams, que aconseguiràs emplenant el got amb aquest pes de fesols o cigrons. (Utilitza la balança).

Cada cop que tinguis un casteller llest tapa la boca del got amb cartolina i enganxa-la amb cola o cinta adhesiva o silicona (el tipus de pega està en funció dels

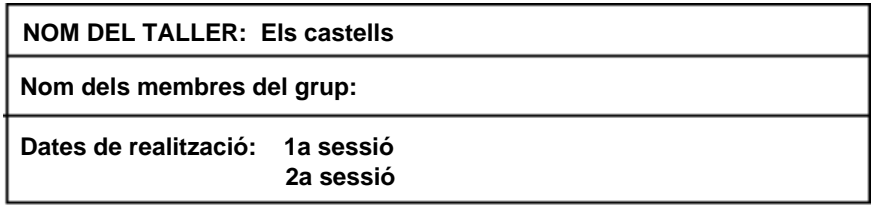

\begin{tabular}{|l|l|}
\hline Organització del grup. & \\
\hline Capacitat de treballar en grup. & \\
\hline $\begin{array}{l}\text { Valoració de les dades (relació pes alça- } \\
\text { da) escollides pel grup per a realitzar } \\
\text { l'activitat. }\end{array}$ & \\
\hline $\begin{array}{l}\text { Arrodoniment de les dades que empren } \\
\text { a la taula per tant de facilitar el càlcul de } \\
\text { resultats. }\end{array}$ & \\
\hline $\begin{array}{l}\text { Capacitat de predicció de resultats i } \\
\text { anàlisi dels mateixos. }\end{array}$ & \\
\hline $\begin{array}{l}\text { Utilització de referents propers (el seu } \\
\text { pes i alçada) per determinar les dades a } \\
\text { emprar en la taula. }\end{array}$ & \\
\hline Precisió en l'ús del estris de mesura. & \\
\hline Planificació de la feina. & \\
\hline Problemes: Seqüenciació del procés. & \\
\hline $\begin{array}{l}\text { Utilització de taules com a presentació } \\
\text { del resultats. }\end{array}$ & \\
\hline $\begin{array}{l}\text { Utilització de dibuixos o esquemes per } \\
\text { representar situacions. }\end{array}$ & \\
\hline Escales: comprensió i ús correcte. & \\
\hline Saben demanar ajut. & \\
\hline $\begin{array}{l}\text { Capacitat d'exposar en públic els resul- } \\
\text { mateixos. } \\
\text { materiència i discussió dels }\end{array}$ & \\
\hline Presentació del dossier del taller. & \\
\hline
\end{tabular}

Fig. 2. Model de registre per controlar el desenvolupament de l'activitat

materials emprats). No et descuidis d'escriure el nom del casteller dins la construcció.

Quan tinguis tots els castellers fets, fes la construcció. Pensa que el castell de veritat seria deu vegades més alt i pesaria 1000 vegades més.

\section{Avaluació}

Durant les sessions de treball la mestra anirà omplint un registre de com es desenvolupa l'activitat, similar al model presentat a la figura 2 (sols hi consten uns quants ítems a observar, comentar i valorar).

Al final de cada taller l'alumne farà un autoinforme valoratiu, destacant quins aprenentatges nous ha fet, 


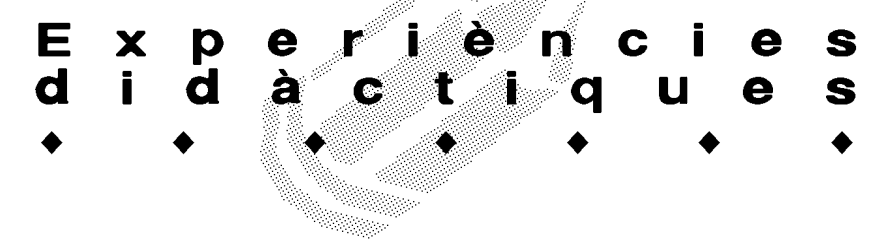

què li ha agradat més de l'activitat, què no li ha agradat tant i possibles modificacions que ell introduiria en el disseny de l'activitat.

Quan s'acaba cada taller, cada grup ha de presentar un dossier on es reculli l'experiència realitzada i els problemes o situacions que s'han plantejat, quin camí han seguit per resoldre'ls i a quins resultats han arribat.

Els grups de treball, un cop han passat pels quatre tallers, presentaran a la resta de companys un informe global de les activitats realitzades (sessió de síntesi). En aquesta sessió els grups avaluen el grup que presenta. Al final del temps pactat sempre s'obre un torn de preguntes.

La mestra valorarà els dossiers de cada taller i comentarà a cada grup els seus treballs, destacant-ne els encerts i clarificant dubtes o errors que han comès. També comenta la valoració feta dels tallers realitzats a cada grup.

\section{Valoració de l'experiència}

La realització del taller ha estat molt positiva per part dels nens ( "M'ho he passat molt bé i he après a fer-me preguntes de coses que no m'havia aturat a pensar mai", "Va ser difícil posar-nos d'acord amb els pesos i les alçades, però quan vam fer la maqueta va ser divertit").

Per part dels mestres també estem satisfets de l'experiència; hem vist participar activament en el taller nens que durant altres sessions de classe mostraven actituds més distants envers les matemàtiques. Amb tot, volem destacar alguns aspectes que ens han cridat l'atenció:
- La no aplicació de referents concrets a l'hora de cercar valors tipus per a cada membre de l'estructura del castell. Els grups es llançaven a dir valors però no s'aturaven a valorar la seva viabilitat.

- La tendència a no arrodonir les dades amb què havien d'operar.

- La dificultat en el moment d'utilitzar amb precisió els estris de mesura.

- La gran participació en el moment de l'exposició de resultats.

- L'acceptació que en una situació oberta hi ha molts camins vàlids per cercar una solució.

- L'entusiasme que en tot moment han manifestat tots els alumnes, principalment en les sessions de construcció a escala de les formacions castelleres treballades.

\section{Agraïments}

Vull fer constar l'agraïment a la Misericòrdia Bach, mestra del CEIP Montsant de Reus, ja que algunes de les idees que han permès desenvolupar aquest treball són seves. També he d'agrair als alumnes de 5è de la meva escola, les sessions invertides en la construcció dels castells que s'exposen en aquest treball.

\section{Referències bibliogràfiques}

GIMÉNEZ, J. Ensenyament i aprenentatge de les matemàtiques: temes clau. Psicopedagogia de les matemàtiques. Edit. UOC. Barcelona. 1997.

GIRONDO, L. Consideracions sobre el treball de resolució de problemes a l'escola. "Comunicació Educativa», 13 (2000) 56-60.

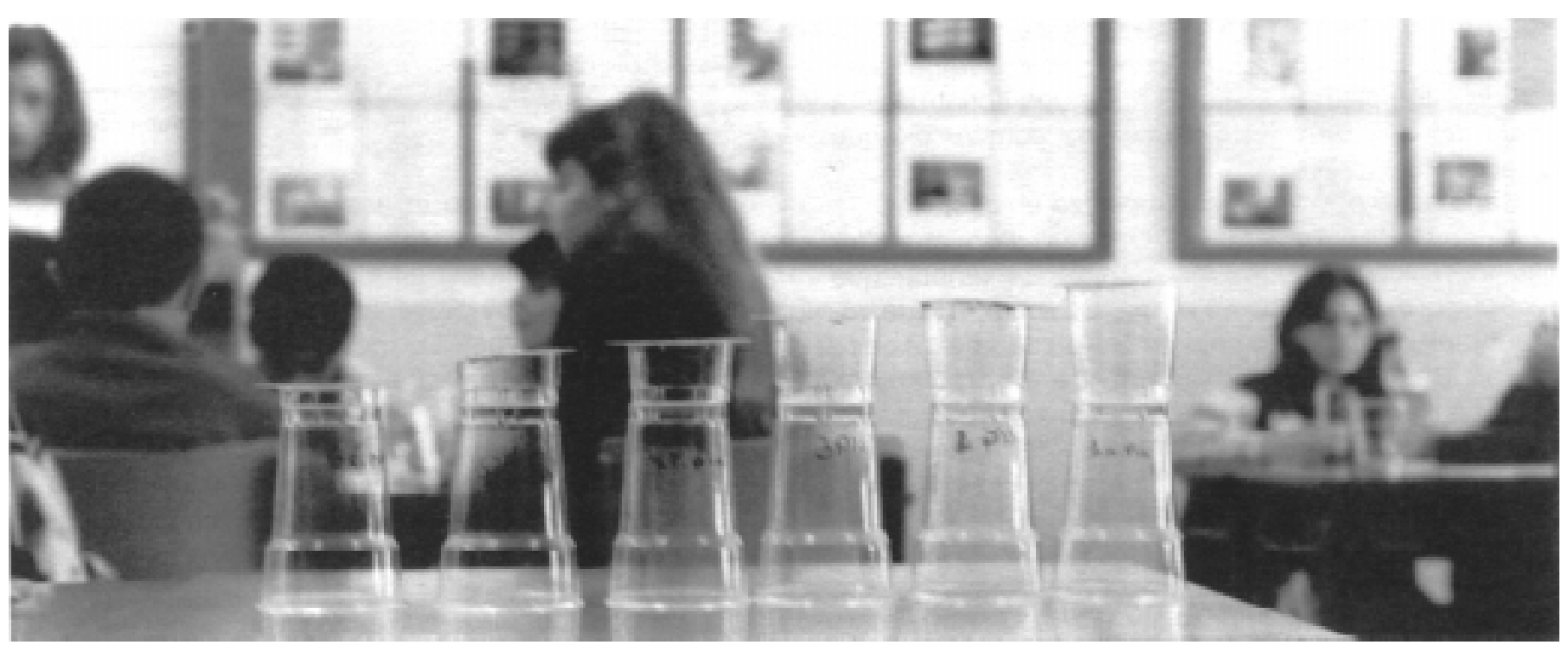

